\title{
Characterization of Nitride Thin Films Using SEM and EDX
}

\author{
F.Z. Mammeri*, L. Chekour And N. Rouag \\ Laboratoire Microstructure et Défauts dans les Matériaux, Université Mentouri Constantine, Algeria
}

\begin{abstract}
The chromium nitride thin films have became more and more popular in the last years because of their very good physical, chemical and mechanical properties. The present study relates to thermal stability of hard thin films of chromium nitride $\mathrm{CrN}$, carried out physical vapour deposition. We studied the influence of the annealing temperature on the morphology of $\mathrm{CrN}$ films, deposited on silicon substrate using magnetron sputtering. The characterizations are examined using scanning electron microscope equipped with energy dispersive X-ray spectroscopy. Annealing treatments in $\mathrm{N}_{2}$ at $600-1000{ }^{\circ} \mathrm{C}$ for $1 \mathrm{~h}$ are performed on CrN coating samples for $530 \mathrm{~nm}$ thickness. At low temperature, the results show a thermal stability of these coatings. $\mathrm{The} \mathrm{Cr}_{2} \mathrm{O}_{3} \mathrm{phase}$ is completely replaced by the $\mathrm{CrN}$ phase at temperature above $1000{ }^{\circ} \mathrm{C}$. The results given by scanning electron microscopy-energy dispersive X-ray spectroscopy and X-ray diffraction are compared.

DOI: 10.12693/APhysPolA.123.294

PACS: 67.25.dp, 68.55.J-, 81.15.-z, 68.37.Hk, 68.90.+g
\end{abstract}

\section{Introduction}

$\mathrm{CrN}$ and $\mathrm{Cr}_{2} \mathrm{~N}$ films possess high melting point, low electrical resistivity, high microhardness and excellent abrasive wear, corrosion as well as oxidation resistance characteristics [1]. The $\mathrm{CrN}$ coating realized industrially by Balzers et al. [2] are stable thermally until $70{ }^{\circ} \mathrm{C}$. Almer et al. [3] observed that beyond $700^{\circ} \mathrm{C}$, the $\mathrm{Cr}_{2} \mathrm{O}_{3}$ appeared in $\mathrm{CrN}$ films and only this oxide remains present at $900^{\circ} \mathrm{C}$. The oxidation of nitrides thin films is an important mechanism leading to the degradation of the mechanical properties at high temperatures $[4,5]$. The chemical reaction between chromium nitride and oxygen gives the following equation:

$2 \mathrm{CrN}+(3 / 2) \mathrm{O}_{2} \rightarrow \mathrm{Cr}_{2} \mathrm{O}_{3}+\mathrm{N}_{2}$.

Thermal oxidation was much studied, for example, in the phase's transformations field [6] and that of the microstructures [7]. The effect of the oxidation at high temperature and on different atmospheres on the mechanical properties of CrN system was studied by Chang et al. [8]. The present study relates to thermal stability of hard thin films of chromium nitride $\mathrm{CrN}$, carried out by physical vapor deposition (PVD).

We studied the influence of the annealing temperature on the morphology of $\mathrm{CrN}$ films deposited on silicon substrate using magnetron sputtering. The characterizations are examined using scanning electron microscope (SEM) equipped with energy dispersive X-ray spectroscopy (EDX). Annealing treatments in $\mathrm{N}_{2}$ at 600 $1000^{\circ} \mathrm{C}$ for $1 \mathrm{~h}$ are performed on $\mathrm{CrN}$ films samples for $530 \mathrm{~nm}$ thickness.

\section{Experimental procedure}

The chromium nitride films were deposited by RF reactive magnetron sputtering. The used substrates were

\footnotetext{
*corresponding author; e-mail: mammeri_f@yahoo.fr
}

silicon single-crystal $\{100\}$. Before deposition, $\mathrm{Cr}$ target and the substrates were cleaned by etching for 5 min in Ar plasma. The deposit films were annealed at different temperatures $600,700,800$, and $1000^{\circ} \mathrm{C}$ for one hour. SEM observations and EDX analyses have been carried out in order to study the effect of annealing treatment on the morphology and the composition of CrN system.

\section{Results and discussion}

SEM surface observations of deposited coatings with $0.5 \mu \mathrm{m}$ of thickness and annealed under $\mathrm{N}_{2}$ atmosphere at $600,700,800$, and $1000^{\circ} \mathrm{C}$ during $1 \mathrm{~h}$ are shown in Fig. 1. The EDX analyses of these films are given in Fig. 2. All spectra reveal the presence of oxygen peak. A decrease of the nitrogen peak is observed when the annealing temperature increases, and vanishes at $1000^{\circ} \mathrm{C}$.

The transformation $\mathrm{CrN} \rightarrow \mathrm{Cr}_{2} \mathrm{O}_{5}$ is associated with nitrogen content decrease [9]. Consequently, when the annealing temperature increases, the contents of nitride and oxides in the film have to decrease and increase, respectively. Indeed, we can see the increase of oxygen peak with the increase of the annealing temperature (Fig. 2), while the nitrogen peak decreases before a complete disappearance at $1000^{\circ} \mathrm{C}$.

Our observations are in according with XRD spectra obtained by Lu and Chen [6]. They carried XRD analyses on $\mathrm{CrN}$ films annealed between 400 and $1200^{\circ} \mathrm{C}$ for $2 \mathrm{~h}$ under air, under $\mathrm{N}_{2}$ and under atmosphere with gas ratio $\mathrm{N}_{2} / \mathrm{H}_{2}=9$. These results revealed that the phase $\mathrm{Cr}_{2} \mathrm{O}_{3}$ appears over $70{ }^{\circ} \mathrm{C}$ for all the atmospheres. But, for the given temperature, its relative intensity decreases with the increase of ratio $\mathrm{PN}_{2} / \mathrm{PO}_{2}$. The CrN phase disappears completely at $1200^{\circ} \mathrm{C}$ and is replaced by $\mathrm{Cr}_{2} \mathrm{O}_{3}$ phase. Their observations for annealing under air were consolidated by more recent work [8].

It is necessary to underline that this different studies use the X-ray diffraction, the results are to leave of a 


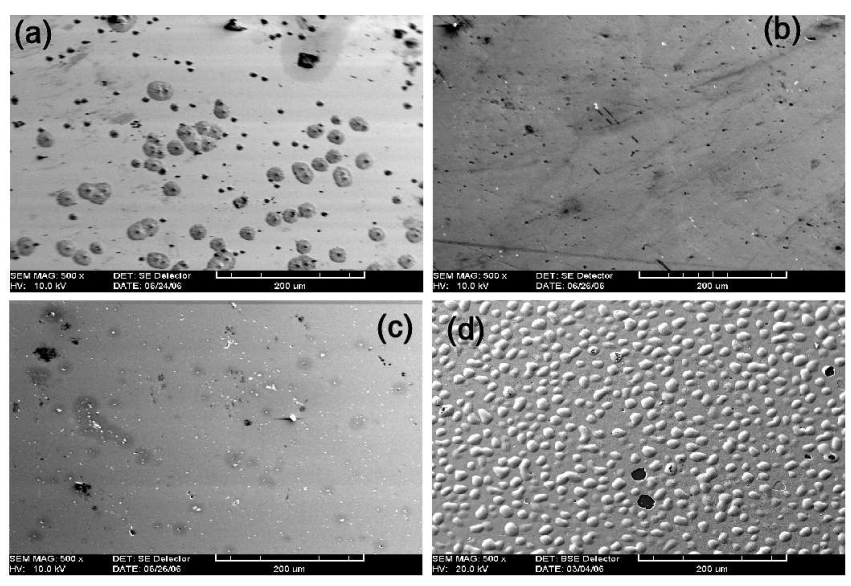

Fig. 1. SEM images of CrN films annealed during $1 \mathrm{~h}$ at: (a) $600{ }^{\circ} \mathrm{C}$, (b) $700{ }^{\circ} \mathrm{C}$, (c) $800{ }^{\circ} \mathrm{C}$, (d) $1000{ }^{\circ} \mathrm{C}$.

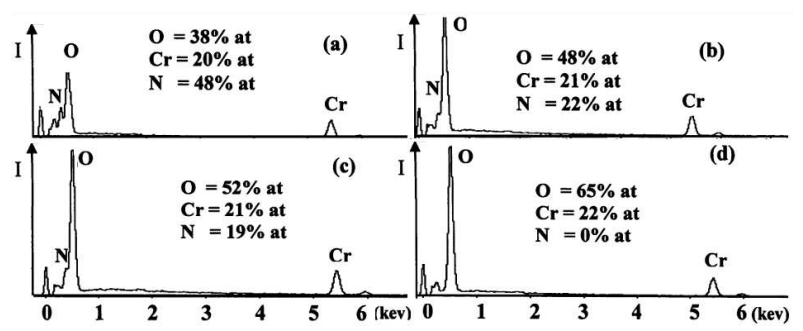

Fig. 2. EDX patterns of $\mathrm{CrN}$ films annealed during 1 hour at: (a) $600{ }^{\circ} \mathrm{C}$, (b) $700{ }^{\circ} \mathrm{C}$, (c) $800{ }^{\circ} \mathrm{C}$, (d) $1000{ }^{\circ} \mathrm{C}$.

global characterization and suppose therefore that the replacement of the $\mathrm{CrN}$ phase by the $\mathrm{Cr}_{2} \mathrm{O}_{3}$ phase makes itself in homogeneous manner on the whole surface. We regrouped in Fig. 3 the $\mathrm{X}$-ray microanalyses done in two different points on the $\mathrm{CrN}$ film of $530 \mathrm{~nm}$ thickness, annealed at $600^{\circ} \mathrm{C}$. We observe the oxygen peak in the two points, but the nitrogen peak exists solely for only one point.

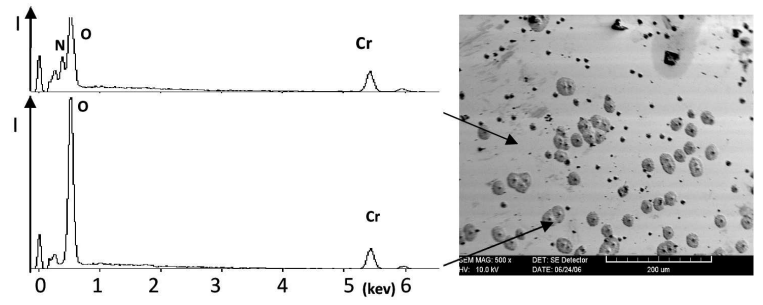

Fig. 2. EDX analyses combined with a SEM micrograph of $\mathrm{CrN}$ film annealed at $600{ }^{\circ} \mathrm{C}$ during 1 hour under $\mathrm{N}_{2}$.

This difference of answers shows that the oxidation does not make itself in a homogeneous way on the whole nitride coating, that is undetectable by X-ray diffraction. This observation permits to support the fact that these are the preferential sites in the $\mathrm{CrN}$ microstructure for the germination of the $\mathrm{Cr}_{2} \mathrm{O}_{3}$ phase. The formation of the oxide probably starts on the grain boundaries of the
CrN phase that it replaces progressively, as it was underlined by the works of Ichumira [10].

He shows that the oxidation of $\mathrm{CrN}$ occurs by the very rapid diffusion of oxygen along the grain boundaries of oxide films formed on each $\mathrm{CrN}$ grain. The rate-determining step of the oxidation of $\mathrm{CrN}$ is the $\mathrm{Cr}$ ion diffusion through the $\mathrm{Cr}_{2} \mathrm{O}_{3}$ formed on each $\mathrm{CrN}$ grain.

\section{Conclusion}

We were interested in this work in the thermal stability of $\mathrm{CrN}$ thin films, deposited on silicon ( $\mathrm{Si}$ ) substrate. The influence of the annealing temperature on the morphological characterization of films was considered.

From $700^{\circ} \mathrm{C}$, there is apparition of oxygen in $\mathrm{CrN}$ films, until $1000^{\circ} \mathrm{C}$, nitrogen is replaced by the oxygen, the $\mathrm{CrN}$ phase disappears and is transformed in $\mathrm{Cr}_{2} \mathrm{O}_{3}$ phase. Chromium nitride films are stable thermally until about $700{ }^{\circ} \mathrm{C}$. The EDX permitted to show the distribution of the phases and complete thus the XRD technique ordinarily used. The oxidization does not make itself in a homogeneous way on the whole coating of nitride, which is not detectable by X-ray diffraction. There are the preferential sites in the $\mathrm{CrN}$ microstructure for the germination of the $\mathrm{Cr}_{2} \mathrm{O}_{3}$ phase. Finally the XRD analysis confirms the good thermal stability of the $\mathrm{CrN}$ coatings. The oxidization begins at about $800^{\circ} \mathrm{C}$ to become widespread at $1000^{\circ} \mathrm{C}$.

\section{Acknowledgments}

Acknowledge grants and other people who have contributed to the work (other than authors) here.

\section{References}

[1] Z.B. Zhao, Z.U. Rek, S.M. Yallisove, J.C. Bilello, Thin Solid Films 472, 96 (2005)

[2] B. Balzers, ww.balinit.balzers.com 21 March (2001).

[3] J. Almer, M. Oden, L. Hultman, G. Hâkansson, J. Vac. Sci. Technol. A 18, 121 (2000)

[4] E. Huber, S. Hofmann, Surf. Coat. Technol. 68-69, $64(1994)$

[5] P. Panjan, B. Navinšek, A. Cvelbar, A. Zalar, I. Milošev, Thin Solid Films 281-282, 298 (1996).

[6] F.-H. Lu, H.-Y. Chen, Thin Solid Films 398-399, 368 (2001)

[7] W.P. Hsieh, C.C. Wang, C.H. Lin, F.S. Shieu, J. Electrochem. Soc. 149, B234 (2002).

[8] K.-L. Chang, S.-C. Chung, S.-H. Lai, H.-C. Shih, Appl. Surf. Sci. 236, 406 (2004).

[9] I. Milošev, H.-H. Strehblow, B. Navinšek, Thin Solid Films 303, 246 (1997)

[10] H. Ichumira, A. Kawana, Central Research Laboratory, Sumitomo Metal Mining Co., Ltd., 18-5, 3 Chome, Nakakokubun Ichikawa-shi, Chiba, 272 Japan, 1993. 